\title{
Evaluasi Program Matrikulasi "TOEFL" Mahasiswa Universitas Al Azhar Indonesia 2010/2011
}

\author{
Ria Herwandar*, Denny Azhari Safryono, Priyanti Yuni Haryono \\ Program Studi Sastra Inggris, Fakultas Sastra, \\ Universitas Al Azhar Indonesia, Jalan Sisingamangaraja, Jakarta, 12110 \\ *Penulis untuk Korespondensi: ria_herwandars@uai.ac.id
}

\begin{abstract}
Abstrak - Penelitian ini menjabarkan proses pembelajaran TOEFL dan hasil temuan terhadap mahasiswa Al Azhar Indonesia angkatan 2010-2011 Program Matrikulasi. Pelatihan TOEFL ini berlangsung 38 jam dilengkapi dengan 4 progressive test. Hasil temuan dari penelitian ini mengungkapkan kelemahan dan kemajuan pada kemahiran bahasa Inggris dengan tampilan kelemahan terutama pada struktur bahasa. Saran dan solusi untuk menanggulangi kelemahan di paparkan berdasarkan hasil test.
\end{abstract}

Abstrak - This research has focused on the process and findings of TOEFL Matriculation which has been conducted to the students of University of Al Azhar Indonesia year 20102011. The course consists of 38 hours TOEFL training and 4 progressive tests. The findings shown of certain progress and weaknesses of proficiency especially in "structure". At the end solution or suggestion are given based on the tests.

Keywords - Evaluation of Matriculation, TOEFL, progressive tests

\section{PENDAHULUAN}

\subsection{Latar Belakang}

TrOEFL (Test of English as A Foreign Language) merupakan jenis tes yang mengukur kemampuan bahasa Inggris seseorang secara akademis dalam berkomunikasi dengan bahasa Inggris. TOEFL berkembang pesat diawali dengan tes berbasis Paper Based kemudian berbasis Computer Based dan terakhir menjadi IBT atau Internet Based TOEFL test. Dalam dunia pendidikan, TOEFL menjadi sangat popular karena hampir semua universitas diseluruh dunia menerapkan persyaratan skor TOEFL bagi calon mahasiswa S2 dan S3 dengan skor minimal ratarata 500 atau 600 tergantung jurusan yang diminati oleh siswa dan kebijakkan universitas.

Persyaratan skor TOEFL juga diterapkan di berbagai situasi calon pegawai negeri maupun pegawai swasta harus mengikuti TOEFL dalam ujian saringan. Karyawan yang akan mendapat jabatan, pangkat, atau golongan yang lebih tinggi harus mengikuti tes TOEFL. Apabila suatu perusahaan atau kantor pemerintahan menyelenggarakan pelatihan jangka pendek atau panjang keluar negeri, maka calon peserta terlebih dahulu harus menjalani TOEFL Dalam perkembangan terkini, tidak hanya calon mahasiswa S2 dan S3 ataupun pegawai negeri yang diharuskan memiliki skor TOEFL, tetapi calon mahasiswa S1 diwajibkan pula memiliki skor TOEFL. Salah satu alasannya adalah bahwa, pendidikan sekarang ini, siswa dituntut memiliki kemampuan menyerap isi buku ajar dalam bahasa Inggris, maka calon mahasiswa S1 diharuskan memiliki skor TOEFL. Walaupun skor diawal tidak diharuskan dengan ketat mencapai nilai tertentu, namun mereka harus menyiapkan diri selama enam semester berikutnya di perguruan tinggi untuk mencapai skor TOEFL di angka 450 untuk mendapat izin mengikuti ujian skripsi. Peraturan ini berlaku di berbagai universitas di Indonesia termasuk di Universitas Al Azhar Indonesia. Bapak Rektor Universitas Al Azhar Indonesia bahkan telah mengeluarkan Surat Keputusan mengenai kepastian bersyarat memiliki skor TOEFL 450 bagi mahasiswa yang akan mengikuti ujian skripsi di semua jurusan bidang studi. Apabila tidak memilik skor TOEFL tersebut maka mereka tidak bisa mengambil ijazah. Keputusan ini dituangkan dalam buku Pedoman Akademik 2009-2010 halaman 4. 
Alasan penting lainnya mengapa TOEFL harus dilaksanakan adalah karena bahasa Inggris menjadi salah satu bahasa asing yang menjadi bagian dari Tujuh Elemen Dasar Universitas Al Azhar Indonesia yang menjadi ciri khas kompetensi mahasiswa Al Azhar.

\subsection{Pembatasan Masalah}

Bagi sebagian besar mahasiswa dan mahasiswi Universitas $\mathrm{Al}$ azhar Indonesia, meraih skor TOEFL yang memadai tidaklah mudah. Mahasiswa baru banyak yang belum pernah belajar bagaimana mengerjakan TOEFL dengan benar. Mereka tidak mendapat pajanan yang cukup untuk membahas tata bahasa atau mendengar percakapan panjang maupun membaca teks yang beragam dengan topik keilmuan yang sangat akademis yang menjadi ciri khas isi materi TOEFL. Mereka belum pernah mengenyam bagaimana harus berstrategi dalam mengerjakan TOEFL. Kemahiran berkomunikasi para siswa sangat beragam, di mana sebagian besar masih jauh di bawah skor TOEFL 400. Beberapa mahasiswa bahkan belum memiliki skor 450 walaupun mereka sudah di ambang ujian skripsi.

Kesulitan yang terbesar adalah tentu TOEFL itu sendiri yang dikenal memiliki tingkat kesulitan yang sangat tinggi. Gramatika dan kosa kata menjadi beban yang berat bagi mahasiswa. Namun, justru pemahaman yang lemah di kedua skill ini akan menghambat pemahaman mereka untuk menjawab bagian Listening, Structure, Written Expression, dan Reading. Menghadapi masalah ini, maka Universitas Al Azhar Indonesia mendelegasikan penyelenggaraan program pelatihan yang bernama "Matrikulasi Bahasa Inggris (TOEFL) kepada Pusat Pengembangan Bahasa dan Budaya untuk tahun program 2011. Program TOEFL 40 jam diharapkan mampu menolong para siswa 2010 untuk lebih awal membenahi kemampuan berkomunikasi baik secara lisan maupun tulisan dalam bahasa Inggris pada ruang lingkup pemahaman akademis melalui TOEFL. Dalam kegiatan Matrikulasi ini diharapkan mereka akan termotivasi dan terbekali dengan pembelajaran maupun strategi menganalisis dan menjawab pertanyaan yang ada pada sistem TOEFL.

\subsection{Rumusan Masalah}

Secara umum masalah pertama yang dihadapi adalah kondisi kemampuan mahasiswa baru Universitas Al Azhar Indonesia dilihat dari kemampuan mendapatkan skor TOEFL Tes awal. Diperkirakan sebagian kecil jumlah siswa mampu mendapat skor TOEFL Tes sesuai nilai yang diharapkan, namun sebagian besar berpredikat lemah karena mereka tidak mampu mengerjakan tes TOEFL dengan baik. Ketidakmampuan mereka dalam mengerjakan tes TOEFL tidak saja karena penguasaan bahasa Inggris mereka masih lemah, tetapi juga karena mereka tidak mengenal dan tidak terbiasa mengerjakan TOEFL sehingga mereka tidak mengenal topic dan jenis kebahasaan Inggris apa yang diujikan dan ketidaktahuan akan strategi dalam melaksanakan ujian TOEFL tersebut.

Kesulitan mahasiswa dalam mengerjakan TOEFL ditemukan dalam tiga kategori pemahaman, yakni pemahaman Listening, Structure and Written Expression, and Reading. Dalam Listening mahasiswa harus memiliki kemampuan untuk mengerjakan 'Structure for Restatements', mengerti jenis percakapan dan memahami 'Topics for Minitalks'. Pada tataran Structure and Written Expression, terdapat bahasan mengenai gramatika secara rinci dan menyeluruh diawali dengan pembahasan kata kerja sampai dengan kosa-kata. Bagian ini sama sulitnya dengan kategori ketiga yakni mengenai Reading. Dalam Reading, mahasiswa harus mampu menguasai kosa kata, sedangkan dalam Reading Comprehension, mahasiswa harus mampu menganalisis melalui tahapan 'previewing, Reading for Main Ideas, Scanning, Inferencing, Restating, dan faktor lainnya.

Menghadapi kesulitan mahasiswa, suatu sistem pembelajaran TOEFL dirancang yang berlangsung dalam sepuluh hari secara intensif. Setiap hari mereka akan mendapat 4 SKS pembelajaran secara sistematis membahas ketiga kemahiran yakni Listening, Structure and Written Expressions, dan Reading. Jumlah tatap muka pembelajaran mencapai 40 jam. Diharapkan pembelajaran ini akan berhasil meningkatkan kemampuan mahasiswa dalam mendapatkan skor TOEFL yang lebih baik dari sebelumnya. Akan terlihat seberapa efektif pembelajaran ini. Mampukah pelatihan ini menghantar mahasiswa menjadi mandiri untuk belajar secara individu untuk terus meningkatkan skor TOEFL setelah diperkenalkan dengan strategi mengerjakan tes tersebut.

Faktor eksternal dan internal dalam proses pembelajaran TOEFL tidak kalah pentingnya Mengamati dan memahami perilaku dan motivasi mahasiswa ketika menghadapi pembelajaran dan 
faktor kesiapan pengajar dalam menyampaikan mata ajar yang efektif akan mengukur kemajuan mereka.

\subsection{Tujuan Penelitian}

Tujuan penelitian ini akan meliputi berbagai faktor yang akan memberikan masukkan positif untuk lebih meningkatkan kemajuan mahasiswa paling sedikit dapat mencapai skor minimal 450 dan membekali para pengajar dalam menangani TOEFL. Temuan yang akan didapat antara lain adalah:

1) Menemukan kisaran peningkatan skor TOEFL para siswa secara maksimal

2) Merinci kelemahan penguasaan bahasa Inggris yang tercermin pada mahasiswa 2010 di level Listening, Structure, Reading yang mungkin menghambat peningkatan skor TOEFL

3) Menemukan pola penanggulangan kesulitan menghadapi materi TOEFL

4) Melihat kelemahan sistem pengajaran TOEFL dalam 40 jam untuk diperbaiki

5) Meningkatkan motivasi dan kemandirian dalam proses pembelajaran TOEFL

6) Mencari penyelesaian terhadap factor eksternal dan internal proses pembelajaran TOEFL.

\section{KERANGKA TEORI/TINJAUAN PUSTAKA}

\subsection{Penelitian Kualitatif}

Syamsuddin dan Damaianti mengatakan bahwa, pendekatan kualitatif sangat penting dipelajari terutama untuk latihan kependidikan dan berdasarkan pada filsafat konstruktif, penelitian kualitatif mengasumsikan realita sebagai sesuatu yang dapat dilihat dari sudut pandang yang berbeda. Interaksi dengan individu dan pengalaman berbagai peristiwa dipahami berdasarkan pemahaman subjektif. Peneliti yang menggunakan metode kualitatif percaya bahwa realita adalah suatu bentuk sosial dengan kata lain, yang menjadi persepsi mereka adalah segala hal yang mereka sadari betul "nyata" hal yang membuat mereka berpikir dan merasakan sesuatu (Syamsuddin \& Damaianti, 2006:74) Di samping itu penelitian kualitatif dapat dilakukan dalam praktik pendididkan dalam membantu proses belajar mengajar sehingga guru dapat melakukan upaya dengan lebih sadar (Syamsuddin \& Damaianti, 2006:77)
Mc Millan \& Schumachter dalam (Syamsuddin \& Damaianti, 2006:73) mendefinisikan bahwa penelitian Kualitatif merupakan suatu pendekatan investigasi karena biasanya peneliti mengumpulkan data dengan bertatap muka langsung dan berinteraksi dengan orang-orang di tempat penelitian.

\subsection{Studi Kasus dan Kepustakaan}

Penelitian ini melibatkan penelitian kepustakaan karena melibatkan pemahaman kemampuan berbahasa yang tercermin dalam kajian materi TOEFL secara textual. Untuk mengaplikasikan temuan kepustakaan ini tidaklah lengkap tanpa melibatkan pendekatan studi kasus karena memang dalam penelitian, studi kasus sering dikaitkan dengan penelitian kualitatif demikian pendapat Bogdan dan Biklen juga Burges dalam (Syamsuddin \& Damaianti, 2006:178). Menurut Ary, Jacobs dan Razavich dalam (Syamsuddin \& Damaianti, 2006:178) menjelaskan bahwa sifat studi kasus adalah pendekatan yang bertujuan untuk mempertahankan keutuhan (wholeness) objek sehingga studi kasus menjadi suatu penelitian yang exploratoris dan deskriptif sifatnya Arikuntoro dalam (Syamsuddin \&Damaianti, 2006:178).

\subsection{Kerangka Pendekatan Pemerolehan Bahasa Kedua, Testing dan Assessment}

Dalam kesuksesan pembelajaran bahasa asing, perlu pemahaman utuh mengenai faktor apa saja yang melibatkan pemerolehan bahasa kedua selain bahasa ibu. Menurut Yorio dalam Brown Douglas (2008:314-315) Klasifikasi variable-variabel pembelajaran adalah sebagai berikut: Pertama faktor usia kanak kanak, remaja dan dewasa. Untuk usia dewasa, pembelajaran bahasa kedua dipengaruhi oleh masa kritis biologis, tekanan kawan sebaya, konteks belajar/mengajar dan bahasa kedua. Variabel ke dua adalah faktor kognisi yang melibatkan kecerdasan umum, bakat bahasa dan strategi pembelajaran seseorang. Variabel ke tiga mengenai kemampuan bahasa asli ditinjau dari transfer fonologis, gramatikal dan semantic. Keempat adalah masukan pada bahasa seseorang apakah melalui pembelajaran bebas atau pembelajaran terbimbing.

Konteks pembelajarannya seperti apa dilihat dari sisi tempat pembelajaran lingkungan bahasa asing atau dwibahasa, jenis kontak bahasa, lingkungan bahasa keluarga, Dalam pembelajaran terbimbing dibahas tipe bimbingan seperti apa. Formal atau 
informal, intensif atau tidak. Lama bimbingan materi dan sumber bimbingan. Variabel kelima mencakup wilayah afektif yang meliputi faktor sosial budaya dimana seseorang bersikap terhadap budaya dan warga asli, budaya dan warga bahasa kedua. Wilayah afektif juga meliputi faktor egosentris pembelajar, misalnya membahas sifat kecemasan, daya resap diri, depresi, penolakan dan lainnya. Yang paling penting dalam variable ini adalah motivasi pembelajar apakah integratif apakah bersifat instrumental dimana pembelajaran tersebut terjadi karena merupakan pilihan sendiri atau pilihan terpaksa. Variabel ke enam dan terakhir adalah faktor latar belakang pendidikan pembelajar. Sistem pendidikannya bagaimana, berapa tahun belajar, bidang studinya apa merupakan unsur-unsur di variabel ini.

Menurut Lightbown dalam Brown (2008:316) Teori pemerolehan bahasa kedua menciptakan hipotesa atau klaim seperti:

1) Para pembelajar menciptakan antarbahasa yang sistematis yang ditandai dengan kesalahan kesalahan yang sama sistematisnya dengan kesalahan kanak-kanak yang mempelajari bahasa tersebut sebagai bahasa pertama, dan juga orang-orang lain yang mendasarkan diri pada bahasa asli mereka sendiri,

2) Ada bagian yang tidak bisa digunakan dalam pemerolehan bahasa sehingga struktur-struktur tertentu harus diperoleh sebelum yang lainnya bisa dipadukan,

3) Praktek berbahasa belum tentu menjadikan sempurna,

4) Bagi kebanyakan pembelajar dewasa, pemerolehan berhenti "memfosil" sebelum pembelajar meraih kecakapan dalam bahasa sasaran yang mendekati kefasihan penutur asli,

5) Orang tidak biasa mencapai pemahaman menyeluruh pada bahasa kedua yang mendekati penutur asli bahasa tersebut hanya dengan satu jam sehari,

6) Pembelajaran memikul beban berat karena bahasa sangat kompleks,

7) Kemampuan seorang pembelajar untuk memahami makna bahasa menurut konteksnya memperluas kemampuannya untuk memahami bahasa yang dilepaskan dari konteks dan untuk memproduksi bahasa yang kompleksitas dan akurasinya setara.

Penelitian ini melibatkan TOEFL tes dan proses pengembangan penerapan pembelajaran tes ini. Maka karena penelitian ini mencerminkan suatu proses pembelajaran, dapat pula disimpulkan, selain membahas mengenai testing, pendekatan assessment turut berperan dalam menjabarkan proses perkembangan pencapaian skor TOEFL para responden.

Brown mengatakan bahwa tes adalah suatu metode pengukuran atau performa terhadap kemampuan, dan pengetahuan seseorang in a given domain. Pertama, Tes adalah suatu metode atau instrument dari seperangkat teknis, prosedur atau rincian yang membutuhkan performa dari mereka yang mengerjakan tes tersebut. Untuk memastikan tes tersebut baik maka metode yang diterapkan haruslah lugas dan terstruktur: jenis pilihan ganda, pertanyaan dengan jawaban yg pasti, jawaban tertulis yang baku dan jenis lainnya. Kedua, Tes harus mampu mengukur, baik dalam mengukur kemampuan umum atau kemampuan khusus, kompetensi atau mengukur objektivitas (Brown $\mathrm{H}$. Douglas, 2004:3)

Lebih jauh ia membandingkan definisi Tes dengan Assessment sebagai berikut: "Tes adalah prosedur administratif yang dipersiapkan dan terjadwalkan dalam kurikulum yg harus dikuasai siswa untuk diperagakan dengan sempurna pada suatu kurun waktu karena jawaban mereka akan diukur dan dievaluasi”.

Sementara Assessment didefinisikan sebagai proses penilaian yang berkesinambungan atau "ongoing progress" yang merangkul cakupan yang lebih luas. Dengan demikian Tes hanyalah merupakan bagian kecil dari assessment. Tes dapat dikategorikan sebagai Summative Assesment termasuk diantaranya quizzes, periodic review test, midterm dan final exams (Brown H. Douglas, 2004:6)

TOEFL Tes dikategorikan sebagai NormReferenced Test karena skor dikaitkan berdasarkan hitungan berjenjang atau memiliki tahapan persentase. Tujuannya adalah mampu menempatkan para siswa secara matematis pada posisi ranking tertentu, misalnya berposisi dengan nilai skor TOEFL 400 dari 700. (Brown H. Douglas, 2004:7). TOEFL ditujukan bagi sejumlah besar peserta yang hasilnya harus tepat dan secepat mungkin ditentukan hasil yang akurat dengan penyelenggaraan yang tidak mahal namun efektif.

Strategi pembelajaran yang terjadi dalam TOEFL merupakan pengembangan "Cognitive Skills". Menurut Weinsteein dan Meyer dalam O'Malley (1995:43), "Learning Strategies" menyediakan fasilitas pembelajaran sebagai tujuan akhir bagi 
siswa. Tujuannya adalah agar mampu meningkatkan dampak motivasional dan kondisi emotive serta bagaimana siswa memahami, memilih, mengorganisasikan dan mengintegrasikan pembelajarannya secara mandiri bagi setiap individu. Strategi pembelajaran dalam TOEFL mampu menjadi siswa seorang pembelajar mandiri melalui "Reading, Listening, Writing dan Speaking Skills" terutama dalam TOEFL Internet Based Test. Sementara, Strategi yang terdapat dalam TOEFL Paper Based yang akan dijabarkan adalah "Listening, Structure and Written Expression dan Reading Skills (Vocabulary and Reading Comprehension)."

Pembelajaran mendengar dengan berdaya kritis dalam TOEFL dilakukan secara intensif. Structure and Written Expression, membahas rincian gramatika secara berurutan dengan analisis yang mendalam. Tes pada tata bahasa TOEFL berlangsung hanya 25 menit. Menurut Grellet (1995:12) dalam memahami suatu text, pembaca harus menggunakan 'Reading Techniques' seperti: Sensitizing by Inferencing through the context and word-formation' Understanding relations within the sentence, Linking sentences and ideas through reference and link-words". Faktor lainnya melibatkan proses membaca dimulai dengan: Predicting, Previewing, Anticipating, Skimming dan Scanning”. Dalam menghadapi teks akademik, pembaca atau siswa harus meningkatkan kemampuan reading speed agar mampu menyelesaikan tugas membaca dengan tepat dan cepat.

\section{METODOLOGI PENELITIAN}

\subsection{Teknik Pengumpulan Data}

Sumber data penelitian adalah seluruh mahasiswa Universitas Al Azhar Indonesia 2010/2011 dari 16 fakultas. Jumlah responden 713 berdasarkan data Biro Akademik UAI per-25 Januari 2011. Jumlah jam pembelajaran 40 jam yang dilaksanakan dalam sepuluh hari. Setiap hari siswa mengikuti 4 sks pembelajaran. Setiap kelas terdiri atas 30 orang mahasiswa. Setiap mahasiswa membawa buku modul dan alat tulis lengkap. Pembelajaran berlokasi di ruang kelas Universitas Al Azhar Indonesia. Pelaksanaan Program Matrikulasi dibagi menjadi dua gelombang mengingat jumlah mahasiswa yang sangat besar. Gelombang pertama dilaksanakan pada tagl 7-19 Februari 2011 (asumsi 365 orang) dan gelombang kedua diselenggarakan pada tanggal 11-21 Juli 2011 (asumsi 366 Orang). Jumlah pengajar yang disediakan sebanyak 12 orang dan mereka pun akan diinterview berkaitan dengan proses pembelajaran TOEFL di kelas.

Peneliti utama adalah dosen tetap Fakultas Sastra Program Studi Sastra Inggris. Dalam program Matrikulasi TOEFL ini berkedudukan sebagai Koordinator Program Matrikulasi. Asisten Peneliti adalah Kepala Sub Bagian Laboratorium Bahasa Universitas Al Azhar Indonesia dan berkedudukan sebagai Staf Teknis Program Matrikulasi. Penelitian ini juga dibantu oleh mahasiswi senior Fakultas Sastra Program Studi Sastra Inggris yang bekerja paruh waktu di Pusat Bahasa dan Budaya.

Bahan ajar yang diberikan adalah: Phillips, Deborah. 2001. Longman Introductory Course for TOEFL for the Computer and Paper Tests. New York: Pearson Education. Jadwal program ke dua gelombang, berikut materi yang berlaku adalah sebagai berikut:

Tabel 1. Pembagian Sesi dan Materi

\begin{tabular}{clcl}
\hline Sesi & \multicolumn{1}{c}{ Materi } & Sesi & \multicolumn{1}{c}{ Materi } \\
\hline 1 & DiagnosticTest & 6 & Structure \\
2 & Structure & 7 & Reading \\
3 & Reading & 8 & Listening \\
4 & Listening & 9 & Post Test \\
5 & Mid Test (Review) & 10 & Final Test \\
\hline
\end{tabular}

\subsection{Proses Pengumpulan Data}

Data dikelompokkan menjadi lima tahap. Tahap pertama adalah pembelajaran, pengadaan Diagnostic Test bagi seluruh peserta dan hasil Test dikumpulkan untuk menjadi prediksi awal tingkat kemampuan siswa. Setelah itu skill Structure, Reading dan Listening diberikan dalam tiga hari secara intensif sesuai dengan bahasan berjenjang yang terdapat dalam buku. Di hari ke lima diadakan Mid-Test. Diharapkan pada tingkat ini sudah terlihat peningkatan skor nilai angka TOEFL. Pada pertemuan tiga hari berikutnya membahas structure, reading, dan listening. Pertemuan ke sembilan diisi dengan Post Test. Hari berikutnya Tes akhir untuk menentukan nilai yang bersertifikasi oleh PPBB UAI.

Kedua, kuestioner diisi oleh mahasiswa untuk mendapatkan informasi mengenai saran, usulan, pendapat, dan kekurangan yang mereka rasakan. Kuesioner ini mencari informasi mengenai 
tanggapan atas bahan ajar TOEFL dan perasaan mereka mengenai pembelajaran secara keseluruhan. Tahap ketiga adalah melihat materi TOEFL dan mengupas secara rinci tingkat kesulitan dan mencoba memahami kebutuhan mahasiswa untuk mampu mencerna TOEFL secara baik dan mandiri. Tahap keempat adalah bertukar pendapat secara informal dengan para pengajar TOEFL mengenai pengalaman mengajar dan interaksi mahasiswa terhadap materi ajar TOEFL. Tahap terakhir adalah mencoba menggabungkan semua data dan melihat secara rinci capaian para mahasiswa pada pelatihan Matrikulasi Bahasa Inggris.

\section{HASIL DAN PEMBAHASAN}

\subsection{Persiapan dan Pelaksanaan Pelatihan}

Mahasiswa angkatan 2010 yang mendaftar di bulan Februari 2011 adalah 210 tetapi yang hadir hanya 155 orang. Sementara mahasiswa yang mendaftar di bulan Juli 2011 berjumlah 422 orang dan yang hadir sebanyak 269. Waktu dan durasi pelaksanaan program adalah: gelombang 1 dilaksanakan pada tanggal 7-19 Februari 2011 dan gelombang kedua, diadakan pada tanggal 11-21 Juli 2011. Durasi 40 jam atau 40 SKS: 10 hari masing masing 4 jam perhari. Lokasi pembelajaran berlangsung di kampus UAI dengan jumlah 30 siswa per kelas kecuali untuk ujian hanya 20 siswa perkelas didampingi satu dosen dan satu pengawas. Pembelajaran TOEFL cukup baik dan lancar. Mahasiswa menjalani semua proses belajar dengan mengacu pada bahan ajar pengarang Phillips, Deborah. 2001. Longman Introductory Course for TOEFL for the Computer and Paper Tests. New York: Pearson dan melaksanakan ujian. Data mengenai hasil ujian yang terdiri dari Diagnostic Pre Test, Post Test, Review Test dan Final Test sudah didapat dan sangat informatif untuk dibahas. Diakhir pembelajaran, mahasiswa mengisi kuesioner berkaitan dengan pengalaman mereka belajar TOEFL. Dari sekian banyak mahasiswa, ada sejumlah mahasiswa yang tidak menyelesaikan atau mengikuti ujian akhir.

\subsection{Hasil Rekapitulasi Matrikulasi Bahasa Inggris 'TOEFL' Gelombang Februari dan Juli 2011}

Dari kedua kelompok kelas, gelombang Februari memiliki kelengkapan capaian keempat tes yang dilaksanakan. Rekapitulasi nilai gelombang Februari menjabarkan temuan perkembangan proses belajar dengan adanya peningkatan capaian skor TOEFL sebagai berikut: Program Studi PAUD mendapatkan nilai berjenjang ke atas pada ke empat test rata-rata siswa dengan capaian 337; 402; 409; 409. Mahasiswa PAUD memiliki kemampuan terendah namun mampu meningkatkan nilai sebanyak 72 angka. Program Studi Arab juga memperlihatkan signifikan peningkatan skor mulai dari rata-rata $350 ; 407 ; 425 ; 430$ atau peningkatan nilai skor 80 . Sastra Cina mendapatkan nilai 433 ; 457; 477; 500. Prodi lainnya mengalami flaktuasi nilai namun di akhir ujian ke empat mayoritas mengalami peningkatan. Contohnya Program Studi informatika mendapat 386; 457. Bioteknologi berkreasi diangka 457; 510. Industri mencapai 422; 468. Dari semua Prodi, hanya Akuntansi yang justru mengalami kemunduran yakni dari 577; menuju 459.

Data ini mencerminkan bahwa pelatihan 40 jam TOEFL mampu meningkatkan skor awal para mahasiswa di level 'nilai rata-rata'. Sementara pada capaian nilai tertinggi pada setiap prodi, juga mampu meningkatkan skor pada ujian akhir seperti yang tercermin pada table nilai tertinggi. Prodi yang mendapat peningkatan nilai akhir pada 'nilai tertinggi“ adalah Ilmu komunikasi, Hubungan Internasional, Sastra Jepang, Sastra Cina, Informatika, Industri dan Bioteknologi. Pada Ilmu komunikasi nilai tertinggi tes pertama di angka 567 menjadi 587 di tes terakhir.

Tingkat kesulitan bahasa Inggris dalam TOEFL dapat ditelusuri dari capaian nilai pada kemampuan mendengar dalam bahasa Inggris, tata bahasanya dan dari kemahiran membaca dan mencari jawaban secara baik. Tujuan dari alasan mengapa mahasiswa diberi diagnostic pre test adalah agar mereka dapat melihat skill apa saja yang mereka tidak pahami sehingga para dosen dapat menjelaskan kelemahan-kelemahan mereka.

Pada pelatihan TOEFL gelombang Juli 2011, data memperlihatkan bahwa dari keseluruhan mahasiswa yang berjumlah sekitar 269 orang dapat diklasifikasikan dalam tiga kelompok lulusan di ujian akhir TOEFL, yakni kelompok lemah di angka skor TOEFL 400-449; kelompok sedang atau madya 450-500; dan kelompok mahir 501-tak terbatas. Jumlah mahasiswa yang berada di kelompok 400-449 adalah 93 orang; dari kelompok 450-500 berjumlah 82 dan terakhir di kelompok tertinggi 501-tak terhingga berada di 49 mahasiswa. 
Dari 422 mahasiswa yang terdaftar, 153 tidak mengikuti ujian akhir dan yang mendapat nilai buruk dan sangat lemah adalah 45 orang, yakni kelompok yang mendapat skor di bawah 400 . Kelompok ini ditambah dengan kelompok yang lemah (skor 400-449) 93 akan menjadi 138 dan menyandang status tidak lulus. Angka 138 merupakan jumlah mahasiswa yang tidak lulus melebihi separuh dari peserta gelombang Juli 2011. Sementara perolehan data pada gelombang Februari adalah 45 orang untuk skor 400-449, 25 orang di bawah skor TOEFL 400, 50 orang dalam kelompok perolehan nilai $450-500$, dan perolehan yang di atas 500-sampai tak terbatas adalah 35 orang. Jumlah gabungan gelombang Februari dan Juli menjadi: pada skor TOEFL 400-449 adalah 138 siswa, pada skor 450- 500 menjadi 132 siswa, pada skor 500sampai tak terbatas berjumlah 84 siswa. Sementara jumlah mahasiswa dengan nilai di bawah skor 400 berjumlah 70 orang. Mahasiswa yang mendapat nilai di atas skor TOEFL $600 \mathrm{ke}$ atas hanya 2 mahasiswa. Mahasiswa yang gagal 208. Ini menandakan bahwa hampir separuh mahasiswa UAI angkatan 2010 harus mendapat pelatihan bahasa Inggris yang berkelanjutan agar mampu memenuhi persyaratan mencapai 450 TOEFL skor, agar mereka menguasai bahasa yang akan atau sudah menjadi bahasa pengantar dalam perkuliahan

\subsection{Bahan ajar TOEFL dan Strategi Pembelajaran}

Pelatihan Matrikulasi Bahasa Inggris TOEFL dilaksanakan oleh para dosen Sastra Inggris. Metode pengajaran disesuaikan dengan kebutuhan pembelajaran TOEFL secara mandiri agar setelah pelatihan, mahasiswa mampu belajar mandiri untuk terus meningkatkan nilai skor TOEFL mereka. Kemahiran yang diutamakan dalam TOEFL Paper Based adalah Listening, Structure and Written
Expression dan Reading. Dengan strategi pembelajaran pada masing-masing kemahiran.

Listening dalam TOEFL dibagi menjadi tiga bagian yakni:

1) Short Dialogues dua baris percakapan diikuti dengan pertanyaan mengenai maksud dari pembicara

2) Long Conversation terdiri dari 60-90 detik percakapan mengenai dunia kemahasiswaan diikuti dengan pertanyaan dan

3) Talk atau percakapan mengenai kehidupan kampus dan topik akademik dan diikuti beberapa pertanyaan. Kemahiran mendengar ini menggarap kemampuan menyerap beragam component skill seperti dalam Listening skill, siswa dilatih untuk mendengar dan menangkap fungsi bahasa yang dijabarkan dalam tiga kelompok yakni:

a. 'Structures for Restatements' seperti; 'Similar Sounds, Synonyms, Homophones, Negatives, negative Emphasis, Exclamations, references, Causatives, correlatives Conjunctions, Comparatives, Conditionals, Concessions, Causals, Cause-and-Result Adjectives, Tag Questions, Passives, Chronological Events';

b. Types of Conversations; 'Direct Conversations, Computation conversation, Place conversations and Implied conversations';

c. 'Topics for Mini-Talks such as; Overheard Conversations, Announcements and Advertisements, News Reports, Weather Reports, Information Speeches, Academic Statements, Class Discussions'.

Tabel 2. Rekapitulasi Kelulusan Matrikulasi 2011

\begin{tabular}{lcccccccccc}
\hline \multirow{2}{*}{ Fakultas } & Jumlah & \multicolumn{4}{c}{ Februari } & \multicolumn{5}{c}{ Juli } \\
\cline { 3 - 10 } & Mahasiswa & Pendaftar & Peserta & Lulus & Gagal & Pendaftar & Peserta & Lulus & Gagal \\
\hline Sains dan & 128 & 41 & 36 & 25 & 11 & 78 & 69 & 38 & 31 \\
Teknologi & & 28 & 12 & 6 & 6 & 66 & 34 & 12 & 22 \\
Sastra & 92 & 20 & 13 & 6 & 7 & 51 & 38 & 13 & 25 \\
Ekonomi & 85 & 49 & 39 & 10 & 29 & 44 & 30 & 12 & 18 \\
$\begin{array}{l}\text { Psikologi dan } \\
\text { Pendidikan }\end{array}$ & 98 & 0 & 0 & 0 & 0 & 34 & 12 & 4 & 8 \\
$\begin{array}{l}\text { Hukum } \\
\begin{array}{l}\text { Ilmu Sosial } \\
\text { dan Ilmu }\end{array}\end{array}$ & 51 & 259 & 69 & 55 & 38 & 17 & 149 & 86 & 52 & 34 \\
$\begin{array}{l}\text { Politik } \\
\quad \text { TOTAL }\end{array}$ & $\mathbf{7 1 3}$ & $\mathbf{2 0 7}$ & $\mathbf{1 5 5}$ & $\mathbf{8 5}$ & $\mathbf{7 0}$ & $\mathbf{4 2 2}$ & $\mathbf{2 6 9}$ & $\mathbf{1 3 1}$ & $\mathbf{1 3 8}$ \\
\hline
\end{tabular}


The Structure and Written Expression sama dengan tata bahasa atau Grammar yang merupakan tonggak dari suatu bahasa. Pembelajaran grammar dibagi menjadi beragam skill. Skill ini meliputi masalah ketatabahasaan seperti: subjects and verbs; objects and prepositions; Present participles; past participles; coordinate connectors; adverb clause connectors; noun clause connectors; noun clause connector/subjects; adjective clause connectors; adjective clause connectors/subjects; agreement after prepositional phrase; agreement agreement after expressions of quantity; agreement after certain words; parallel structure with coordinate conjunctions; parallel structure with pair conjunctions; past participles after have; present participles or past participles after be; base form verbs after modals; singular and plural nouns; countable and uncountable nouns; subject and object pronouns; possessives; pronoun reference; adjectives and adverbs; adjectives after linking verbs;

Reading skill meliputi kajian mengenai bagaimana memahami: main idea questions; stated detail questions; find 'unstated' details; implied detail questions; vocabulary in context questions; 'where' questions. Seluruh pertanyaan diberikan dalam bentuk pilihan ganda dengan beragam topik wacana seperti topik kelautan, antariksa, biologi, dan mencakup hampir seluruh topic keilmuan. Mahasiswa dituntut untuk menguasai topik beragam keilmuan dan mampu memahami kosa kata untuk masing-masing disiplin ilmu. Tujuan dari pajanan keilmuan karena tujuan TOEFL adalah mempersiapkan para lulusan sekolah menengah untuk melanjutkan studi ke jenjang yang lebih tinggi baik di luar maupun dalam negeri. Para dosen disamping harus membekali siswa dengan isi kemahiran kebahasaan, mereka juga harus membekali mahasiswa dengan strategi dalam mengerjakan TOEFL.

Tabel 3 memperlihatkan bahwa kesulitan mahasiswa di kedua gelombang ada pada Struktur bahasa, sedangkan Listening dan Reading berimbang dalam tingkat kemahiran.

Tabel 3. Nilai Rata-rata Kemampuan Mahasiswa

\begin{tabular}{llll}
\hline Gelombang & Listening & Structure & Reading \\
\hline Februari & 48,21 & 41,16 & 48,04 \\
Juli & 47,59 & 39,59 & 48,24 \\
\hline
\end{tabular}

Masa kini mahasiswa mudah mendapat kesempatan mendengar dalam bahasa Inggris dan ini tercermin dari hasil nilai rata rata Listening. Dapat disimpulkan bahwa kemahiran mendengar tidak semata-mata hasil latihan listening di kelas tetapi karena mudah mendapat pajanan listening di luar kelas. Nilai rata-rata reading yang mencapai 48,24 cukup mengesankan. Walau reading tergolong sulit dalam TOEFL, namun hasilnya cukup memuaskan, Structure adalah kesulitan utama dan nilai rata-rata begitu rendah apabila dibandingkan dengan kedua skill lainnya. Hal ini terjadi karena Structure merupakan ilmu yang tidak ramah dan menjadi asing untuk dipelajari. Structure tidak membumi bagi mahasiswa dan mereka hanya perlu mengetahui karena harus mengerjakan TOEFL semata. Dengan temuan di atas, para pengajar dapat memfokuskan cara yang terbaik untuk mengajarkan struktur di kemudian hari. Bagaimana struktur dapat menjadi mudah dipahami dan menarik untuk ditekuni.

\subsection{Kuesioner dan Masalah yang Dihadapi}

Pada saat memberikan sertifkat, para mahasiswa diminta untuk mengisi kuesioner mengenai pembelajaran TOEFL. Jawaban mereka dapat mengindikasikan beberapa masukkan. Mereka banyak yang mengakui bahwa matrikulasi bermanfaat dan perlu diadakan. Namun mereka tidak yakin matrikulasi akan efektif apabila harus diberikan melalui Crash Programme. Mereka memilih untuk mengikuti kursus 2 kali seminggu daripada setiap hari dalam 10 hari saja. Mengenai kemahiran bahasa, banyak yang mengalami kesulitan terutama dalam Structure and written Expression, namun secara keseluruhan semua mahasiswa mengakui mempunyai kesulitan dalam Listening, Reading and Structure and Written Expressions.

Analisis dari percakapan informal diantara para dosen adalah rendahnya motivasi para mahasiswa yang mengikuti TOEFL. Faktor ini dapat dimengerti karena program matrikulasi bukan merupakan mata kuliah ber SKS sehingga tidak ada keharusan untuk masuk. Alasan lain adalah TOEFL memang bukan ilmu yang disukai sehingga mereka hanya masuk untuk mendapat nilai baik tanpa didukung oleh keingintahuan yang lebih besar dari diri sendiri. Faktor internal ini sangat penting untuk diperhatikan karena keberhasilan pembelajaran sangat ditentukan oleh motivasi yang tinggi. 
Matrikulasi dilaksanakan pada masa libur perkuliahan. Bagi kelompok gelombang Februari, matrikulasi dapat dikatakan berhasil karena mereka memiliki libur yang tidak lama dan mahasiswa melaksanakan program tersebut dengan baik walau dalam jumlah yang tidak besar. Matrikulasi pada bulan Juli yang diharapkan akan lebih baik dan sempurna karena menghadapi libur panjang, ternyata tidak sesuai dengan yang diharapkan. Presentasi ketidakhadiran terlihat jelas. Alasan mereka bervariasi. Misalnya, beberapa mahasiswa bekerja paruh waktu dalam libur panjang, ada yang pulang ke daerahnya masing-masing. Ada yang berlibur ke luar negeri atau mengikuti kursus tertentu dalam libur panjang di bulan juli.

Di samping motivasi yang rendah, para dosen mengakui bahwa tingkat kemampuan bahasa Inggris Mahasiswa secara umum rendah, sehingga harus membahas TOEFL dari dasar dan dengan waktu 40 jam tentu tidak dapat dengan sempurna memberikan dampak yang memuaskan. TOEFL yang diberikan kepada siswa adalah TOEFL dasar dan ini pun masih sulit untuk dicerna oleh sebagian besar mahasiswa.

\section{KESIMPULAN}

Secara keseluruhan Matrikulasi Bahasa Inggris TOEFL telah dilaksanakan dengan hasil baik. Hasil pembelajaran 40 jam TOEFL menghasilkan kelulusan 84 mahasiswa dengan predikat memuaskan dengan nilai di atas skor TOEFL 501, 132 mahasiswa dengan predikat baik di atas skor TOEFL 450. Jumlah mahasiswa yang tidak lulus 305 mahasiswa dengan perolehan di bawah skor TOEFL 400.

Keberhasilan matrikulasi ini dapat dilihat dengan adanya tingkat kenaikan skor TOEFL pada setiap test yang diselenggarakan dalam 4 tahapan yakni Diagnostic Pre Test, Post Test Review Test dan Final test. Yang didata dari data gelombang Februari. Namun kenaikkan tersebut tidak terlalu tinggi karena pajanan pembelajarannya hanya 40 jam saja.

Tingkat motivasi pada kedua gelombang berbeda. Mahasiswa gelombang Februari cenderung lebih disiplin dan mengikuti pelatihan dengan baik secara menyeluruh. Sementara peserta pada gelombang Juli memperlihatkan banyak ketidakhadiran pada pelatihan.
Jumlah waktu pelatihan yang berdurasi 40 jam ternyata tidak terlalu cocok untuk pembelajaran pada level sangat lemah yang tercermin pada 305 mahasiswa yang tidak lulus dan tidak mendapat sertifikat. Apabila dilihat dari sudut pandang kepentingan mahasiswa yang lemah ini, matrikulasi tidak memberi manfaat karena tidak dapat menghantar mereka untuk mendapat sertifikat kelulusan.

Dari perolehan hasil pembelajaran TOEFL 40 jam dapat disarankan beberapa usulan:

1) Mahasiswa harus dites tingkat kemampuannya agar dapat dimasukkan pada kelas yang sesuai dengan kemampuan awal mereka apakah di tingkat dasar, menengah atau mahir. TOEFL harus dilaksanakan dalam tahapan yang masing-masing tahapan berdurasi dari 40 sampai 50 jam. Pembagian ini untuk mampu mendorong mahasiswa fokus terhadap masalah TOEFL mereka. Apabila dilaksanakan berdasarkan tingkat kemampuannya maka mereka akan melihat proses pembelajaran.

2) Bagaimana meningkatkan motivasi dalam mempelajari TOEFL. Dosen dan penyelenggara Matrikulasi harus duduk bersama untuk mencari jalan keluar dari masalah motivasi ini. Apakah akan diberikan hadiah atau dimasukkan sebagai bagian dari MKU atau diberi pencerahan sebelum pelatihan dimulai.

3) Persiapan para pengajar untuk selalu memberikan yang terbaik pada mahasiswa. Bagaimana mengajar dengan jelas, menarik dan mampu memotivasi siswa. Dosen matrikulasi harus diberikan workshop untuk saling memberi pengalaman dan belajar meningkatkan kemampuan mengajar TOEFL baik paper based TOEFL maupun internet based TOEFL IBT.

4) Perlu sosialisasi kepada mahasiswa dan dosen tentang perlunya Matrikulasi Bahasa Inggris TOEFL

5) Sebaiknya dosen yang mampu mengajar dengan bahasa Inggris agar didorong untuk mengajar dengan bahasa Inggris supaya mahasiswa termotivasi.

6) Setelah 2 tahun Matrikulasi berjalan, sebaiknya ada saran dari tim penyelenggara agar kuliah diberikan dalam bahasa Inggris

7) Perlu ada kajian lebih lanjut dan dipecahkan mengapa hasil akhir dari program matrikulasi ada yang turun. 


\section{DAFTAR ACUAN/PUSTAKA}

[1] Brown Douglas, Language Assessment- Principle and Classroom Practices. San Francisco State university, 2004.

[2] Brown Douglas, Prinsip Pembelajaran dan Pengajaran Bahasa.Kedutaan Besar America Serikat di Jakarta ,2008

[3] Grellet francoise, Developing Reading skills. Cambridge University Press, 1995

[4] Hammer Jeremy, The Practice of English Language Teaching.Longman Group UK Limited 1991
[5] O’Malley J, Chamot Anna Uhl, Learning Strategies in Second Language acquisition. Cambridge University Press ,1990.

[6] Phillips Deborah, Complete Course for TOEFL Preparation for the computer and Paper Tests. New York: Pearsons education 2001

[7] Rogers Bruce, TOEFL Success. Heinle \& Heinley/TTP, 1996.

[8] Sharpe Pamela J, Test of English as a Foreign Language. The Ohio State University 2008

[9] Sharp Pamela J, TOEFL IBT Internet Based Test, Barron's Educational Series, 2010

[10] http://www.TOEFL.org.

[11] www. Petersons.com

[12] www.ets.org 